PREPARED FOR THE U.S. DEPARTMENT OF ENERGY, UNDER CONTRACT DE-AC02-76CH03073

PPPL-3860

PPPL-3860

UC-70

New Benchmarks from Tokamak Experiments for Theoretical Calculations of the Dielectronic Satellite Spectra of Helium-like Ions

by

M. Bitter, M.F. Gu, L.A. Vainshtein, P. Beiersdorfer, G. Bertschinger, O. Marchuk, R. Bell, B. LeBlanc, K.W. Hill, D. Johnson, and L. Roquemore

August 2003
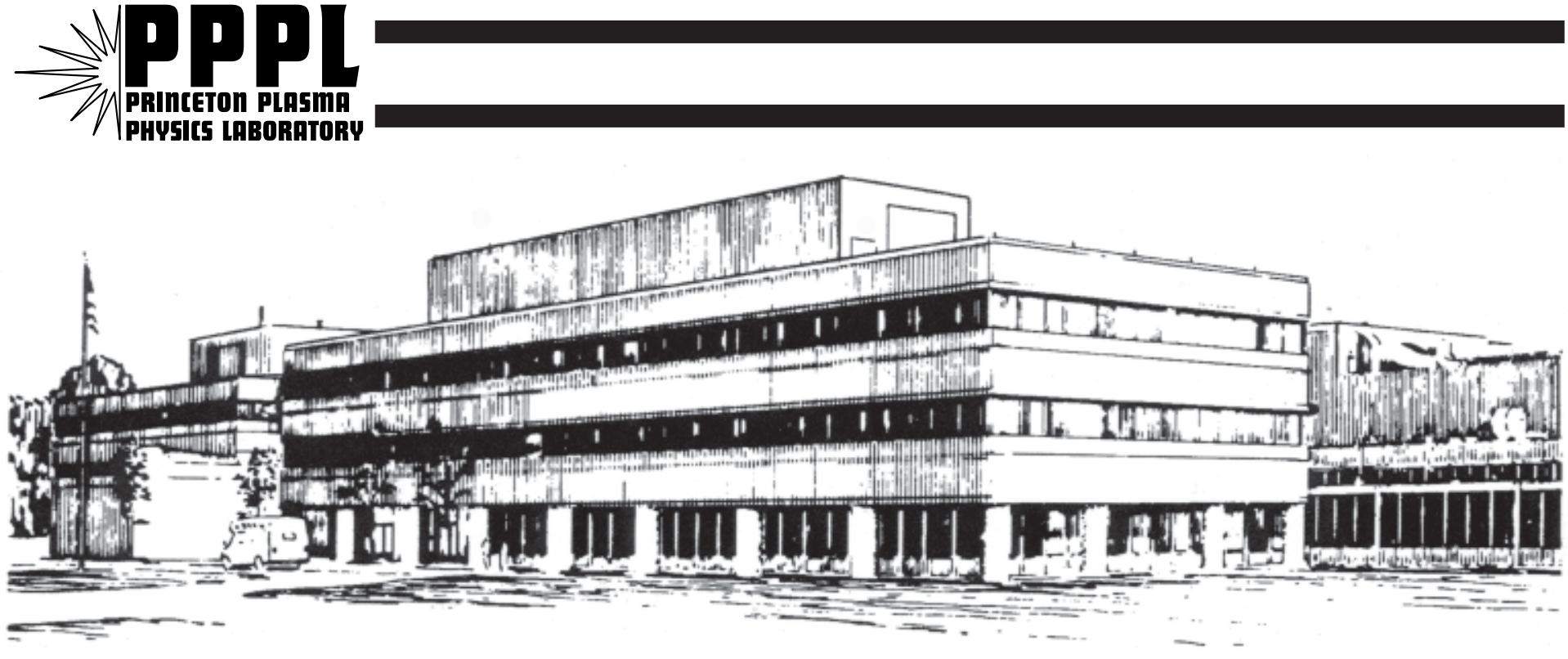

PRINCETON PLASMA PHYSICS LABORATORY PRINCETON UNIVERSITY, PRINCETON, NEW JERSEY 


\section{PPPL Reports Disclaimer}

This report was prepared as an account of work sponsored by an agency of the United States Government. Neither the United States Government nor any agency thereof, nor any of their employees, makes any warranty, express or implied, or assumes any legal liability or responsibility for the accuracy, completeness, or usefulness of any information, apparatus, product, or process disclosed, or represents that its use would not infringe privately owned rights. Reference herein to any specific commercial product, process, or service by trade name, trademark, manufacturer, or otherwise, does not necessarily constitute or imply its endorsement, recommendation, or favoring by the United States Government or any agency thereof. The views and opinions of authors expressed herein do not necessarily state or reflect those of the United States Government or any agency thereof.

\section{Availability}

This report is posted on the U.S. Department of Energy's Princeton Plasma Physics Laboratory Publications and Reports web site in Fiscal Year 2003. The home page for PPPL Reports and Publications is: http://www.pppl.gov/pub_report/

DOE and DOE Contractors can obtain copies of this report from:

U.S. Department of Energy

Office of Scientific and Technical Information

DOE Technical Information Services (DTIS)

P.O. Box 62

Oak Ridge, TN 37831

Telephone: (865) 576-8401

Fax: (865) 576-5728

Email: reports@adonis.osti.gov

This report is available to the general public from:

National Technical Information Service

U.S. Department of Commerce

5285 Port Royal Road

Springfield, VA 22161

Telephone: $1-800-553-6847$ or

(703) $605-6000$

Fax: (703) 321-8547

Internet: http://www.ntis.gov/ordering.htm 


\title{
New Benchmarks from Tokamak Experiments for Theoretical Calculations of the Dielectronic Satellite Spectra of Helium-like Ions
}

M. Bitter ${ }^{1}$, M. F. Gu ${ }^{2}$, L. A. Vainshtein ${ }^{3}$, P. Beiersdorfer ${ }^{4}$, G. Bertschinger ${ }^{5}$, O. Marchuk ${ }^{5}$,

\author{
R. Bell ${ }^{1}$, B. LeBlanc ${ }^{1}$, K. W. Hill ${ }^{1}$, D. Johnson ${ }^{1}$, L. Roquemore ${ }^{1}$ \\ ${ }^{1}$ Princeton Plasma Physics Laboratory, Princeton, NJ 08543 \\ ${ }^{2}$ Center for Space Research MIT, NE80-6083 \\ ${ }^{3}$ Lebedev Physical Institute, Moscow \\ ${ }^{4}$ Lawrence Livermore National Laboratory, Livermore, CA 94550 \\ ${ }^{5}$ Institut für Plasmaphysik Forschungszentrum Jülich, Germany
}

\begin{abstract}
Dielectronic satellite spectra of helium-like argon, recorded with a high-
resolution X-ray crystal spectrometer at the National Spherical Torus Experiment, were found to be inconsistent with existing predictions resulting in unacceptable values for the power balance and suggesting the unlikely existence of non-Maxwellian electron energy distributions. These problems were resolved with calculations from a new atomic code. It is now possible to perform reliable electron temperature measurements and to eliminate the uncertainties associated with determinations of non-Maxwellian distributions.
\end{abstract}

PACS: 52.20.Hv, 52.70.La, 32.30.Rj, 34.80.Lx 
The theory of the dielectronic satellite spectra of helium-like ions, which are widely used for the diagnosis of stellar flares, tokamak plasmas, and laser-produced plasmas, has been continuously improved during the last decades to satisfy the demands for accurate atomic data and to establish a solid base for the development of the theory for more complex ions with more than two electrons. As a result, several numerical codes, which are based on different theoretical approaches and relativistic approximations, are now available. An extensive comparison of the predictions from three widely used codes, the $\mathrm{MZ}$, AUTOLSJ and YODA codes, with solar flare spectra of helium-like iron was recently presented by Kato et al. [1]. Kato found that the predictions from the three codes for the main satellite lines were to within $20 \%$ in agreement with each other and that synthetic spectra constructed from each individual code were in good general agreement with the experimental data. However, it is fair to say that the spectral resolution and statistics of the considered solar flare spectra were insufficient for a detailed comparison with the theoretical predictions, since on the basis of these experimental data it was not possible to make a distinction between the predictions from the different codes or to detect inherent inconsistencies. In particular, the predictions for the numerous dielectronic satellites in the neighborhood of the helium-like resonance line, which are associated with principal quantum number $n=3$ and which are commonly used to infer the existence of nonMaxwellian electron energy distributions in solar flares and tokamaks [2,3], could not be tested. Earlier observations of the FeXXV satellite spectra in plasmas of the Princeton Large Torus were in good general agreement with theoretical predictions, but we point out that there were deviations between the AUTOSLJ code values and the experimental data for the ratio of the $n=2$ and $n=3$ satellites [4]. The $K \beta$ branch of these satellites also 
plays an important role in the electron density and temperature measurements of inertial confinement fusion plasmas [5].

An experimental investigation of these satellites requires measurements with highresolution instruments from well diagnosed plasmas of sufficiently low electron temperature where these features become prominent. Such conditions are now available at the National Spherical Torus Experiment (NSTX) in Ohmically heated plasmas which have electron temperatures in the range from 0.3 to $1.2 \mathrm{keV}$ and ion temperatures below $0.5 \mathrm{keV}$. This range of temperatures is particularly well suited for investigations of the satellite spectra of helium-like argon, ArXVII, which are the subject of this Letter. We note that the temperatures in these Ohmic discharges at NSTX are much lower than those found in typical tokamaks, such as the Joint European Torus, Alcator, or Textor [6], which unlike NSTX have a high aspect ratio of the major and minor plasma radii.

In the following we demonstrate that there are still discrepancies between the existing theory and measurements of ArXVII satellite spectra from NSTX, which lead to unacceptable uncertainties in the electron-temperature measurements. These discrepancies are resolved by new, more detailed theoretical calculations. A satellite spectrum of ArXVII, which was observed with the NSTX high-resolution crystal spectrometer [7], is shown in Fig. 1. The spectral data were accumulated from six nearly identical discharges during the time interval of steady state conditions to reduce the statistical error. The spectrum spans the wavelength range from 3.94 to $4.00 \AA$ and consists of the characteristic helium-like lines of ArXVII, i.e. the $1 \mathrm{~s}^{2}{ }^{1} \mathrm{~S}_{0}-1 \mathrm{~s} 2 \mathrm{p}{ }^{1} \mathrm{P}_{1}$ resonance line (w), the intercombination lines $1 \mathrm{~s}^{2}{ }^{1} \mathrm{~S}_{0}-1 \mathrm{~s} 2 \mathrm{p}{ }^{3} \mathrm{P}_{2}(\mathbf{x})$ and $1 \mathrm{~s}^{2}{ }^{1} \mathrm{~S}_{0}-1 \mathrm{~s} 2 \mathrm{p}{ }^{3} \mathrm{P}_{1}$ $(\mathbf{y})$, and the forbidden line $1 \mathrm{~s}^{2}{ }^{1} \mathrm{~S}_{0}-1 \mathrm{~s} 2 \mathrm{p}{ }^{3} \mathrm{~S}_{1}(\mathbf{z})$, and numerous lithium-like satellites due to transitions $1 \mathrm{~s}^{2} n 1-1 \mathrm{~s} 2 \mathrm{p} n 1$ with $n \geq 2$. The helium-like lines and the prominent lithiumlike satellites $\mathbf{q}, \mathbf{r}, \mathbf{a}, \mathbf{k}$ and $\mathbf{j}$ with $n=2$ have been identified with Gabriel's notation [8]. Most of the lithium-like satellites, with the exception of the $1 s^{2} 2 s-1 s 2 s 2 p$ satellites $\mathbf{q}$ and $\mathbf{r}$ whose upper levels can be populated by inner-shell excitation from the lithium-like ground state, are produced in the process of dielectronic recombination of the helium-like ion by resonant capture of an electron into a doubly excited lithium-like state $1 \mathrm{~s} 2 \mathrm{p} n \mathrm{l}$ [9]. 
This state can decay by autoionization, the reverse process of resonant electron capture, or by stabilizing radiative transitions, such as $1 \mathrm{~s} 2 \mathrm{pnl}->1 \mathrm{~s}^{2} \mathrm{nl}$ giving rise to an observable satellite line near the resonance line $\mathbf{w}$, or other radiative cascades $1 \mathrm{~s} 2 \mathrm{p} n 1$-> $1 \mathrm{~s} 2 \mathrm{p} n{ }^{\prime} \mathbf{l}^{\prime}$ giving rise to lines in other spectral bands. The intensity of the dielectronic satellites is therefore determined by the electron energy distribution and the branching ratios for radiative and autoionizing transitions. For a Maxwellian distribution, the dielectronic satellite intensities are a function of the electron temperature and proportional to the electron density and density of the helium-like ions [10]. With increasing principal quantum number $n$, the wavelengths of the dielectronic satellites converge to the wavelengths of helium-like resonance and intercombination lines [10,11].

The electron temperature is usually determined from the intensity ratios of the strong $n=2$ dielectronic satellites $\mathbf{j}$ and $\mathbf{k}$ with respect to the helium-like resonance line $\mathbf{w}$, whose emissivity is given by

$$
\varepsilon_{w}=N_{e} N_{H e} C\left(T_{e}\right)
$$

where $\mathrm{N}_{\mathrm{e}}$ and $\mathrm{N}_{\mathrm{He}}$, are the electron density and density of the helium-like ions, and $\mathrm{C}\left(\mathrm{T}_{\mathrm{e}}\right)$ is the effective rate coefficient for electron impact excitation. In the ArXVII spectrum, only $\mathbf{k}$ can be used because $\mathbf{j}$ is blended with $\mathbf{z}$. However, the high-resolution spectrometers in tokamak experiments, which are designed for Doppler broadening and Doppler shift measurements capable of resolving wavelength shifts of less than $10^{-4} \AA$, provide spectra in which a substantial part of the $n=3$ satellites is well resolved from the resonance line w (see Fig. 1). It is therefore possible to determine the electron temperature also from the ratios of the resolved $n=3$ dielectronic satellites with respect to the resonance line $\mathbf{w}$ and from the ratio of the $n=3$ to $n=2$ satellites. For a Maxwellian energy distribution one expects to obtain a unique electron temperature value from these three ratios. Disagreement among the inferred temperature values is generally taken as evidence for the existence of a non-Maxwellian distribution $[2,3]$. 
The analysis of the spectral data was performed by a least-squares fit comparison with synthetic spectra constructed from the predictions of the MZ code [12]. The MZ code was chosen since it provides the most accurate wavelengths, which are typically in agreement with the experimental wavelengths to within a few $10^{-4} \AA$. The results of this comparison are shown Figs. 1(a) and 1(b). We found that the very detailed spectral predictions from the $\mathrm{MZ}$ code were in excellent agreement with the experimental data, but that it was not possible to fit the entire spectrum with a unique value for the electron temperature. In fact, the electron temperatures inferred from the fitted ratios of the $n \geq 3$ satellites (Fig. 1(a)) and the $\mathrm{n}=2$ satellite $\mathbf{k}$ (Fig. 1(b)), with respect to the resonance line $\mathbf{w}$, were $\mathrm{T}_{\mathrm{e}}=0.73 \pm 0.01 \mathrm{keV}$ and $\mathrm{T}_{\mathrm{e}}=0.62 \pm 0.01 \mathrm{keV}$, respectively, where the error bars indicate the statistical error. These results suggested the existence of a non-Maxwellian distribution, which, however, is unlikely in steady-state, ohmically heated NSTX plasmas with central electron densities of $5 \times 10^{13} \mathrm{~cm}^{-3}$. Moreover, the results from the spectral data were in disagreement with independent measurements of the electron temperature by the Thomson scattering system [13] and led to unacceptable assumptions for the energy transport and the values of the power balance of the NSTX plasmas.

The synthetic spectra shown in Figs. 1(a) and 1(b) were constructed in several steps using the procedure outlined in [14] by first determining the electron and ion temperatures from the resonance line and $n \geq 3$ satellite lines in the wavelength range from 3.94 to $3.96 \AA$, and then extending the fit to the remaining spectral features in the wavelength range from 3.96 to $4.00 \AA$ A. In Fig. 1(a) the electron temperature was determined from a fit of the $n \geq 3$ satellites and $\mathbf{w}$ and in Fig. 1(b) the electron temperature was determined from the ratio of $\mathbf{k}$ and $\mathbf{w}$. The intensities of the helium-like lines $\mathbf{w}, \mathbf{x}, \mathbf{y}$, and $\mathbf{z}$ were calculated using the recent rate coefficients for electron impact excitation from Keenan [15]. Electron impact excitation is by far the dominant line formation process for $\mathbf{w}$. Empirical enhancement factors were applied to lines $\mathbf{x}, \mathbf{y}$, and $\mathbf{z}$ to account for additional excitation processes which play a strong role for the triplet lines [14]. An expression analog to Eq. (1) was used for the inner-shell excited $1 s^{2} 2 s-1 s 2 p 2 s$ satellites, $\mathbf{q}$ and $\mathbf{r}$, replacing $\mathrm{N}_{\mathrm{He}}$ by $\mathrm{N}_{\mathrm{Li}}$, the density of the lithium-like argon ions [8]. 
The conflicting electron-temperature results inferred from the fits in Figs. 1(a) and 1(b) pointed to possible omissions of radiative branches and levels in the MZ code, and motivated extensive calculations with a new atomic physics code, the Flexible Atomic Code [16], which included all levels and autoionizing and radiative branches, such as the $\mathrm{K} \beta$ branch. The main difference between the predictions from the $\mathrm{MZ}$ code and the Flexible Atomic Code resides, therefore, in the calculation of the $F_{2}$ line factors (as defined in [10]) - or branching ratios - for the $n \geq 3$ satellites. The $\mathrm{F}_{2}$ values obtained from the $\mathrm{MZ}$ code are systematically higher than those from the Flexible Atomic Code. A comparison of the obtained $\mathrm{F}_{2}$ factors for some prominent dielectronic satellites is given in Table I.

A least-squares fit comparison of a synthetic spectrum constructed from the new calculations, by the same procedure as before, with the experimental data is shown in Fig. 1(c). This synthetic spectrum provided, within the experimental uncertainties, a fit of all the spectral features with a unique electron temperature value of $T_{e}=0.58 \pm 0.01 \mathrm{keV}$. The value of the ion temperature was $\mathrm{T}_{\mathrm{i}}=0.45 \pm 0.04 \mathrm{keV}$. However, like most other codes the Flexible Atomic Code yields less accurate wavelengths than the MZ code. For the construction of the synthetic spectrum shown in Fig. 1(c) we, therefore, adopted only the $\mathrm{F}_{2}$ line factors from the Flexible Atomic Code, while wavelengths were still taken from the $\mathrm{MZ}$ code. In order to confirm the uniqueness of the temperature value, we employed a third way of determining the temperature using the ratio of the resolved $n=3$ satellites and line $\mathbf{k}$ [2]. This ratio does not involve the use of line $\mathbf{w}$ and therefore is not sensitive to the tail of the electron energy distribution. From this ratio we obtained $T_{e}=0.56 \pm 0.03$ $\mathrm{keV}$, which is in excellent agreement.

The temperatures inferred from the spectral fits using the Flexible Atomic Code are also in excellent agreement with independent measurements by the Thomson scattering system. A comparison of the time histories of the peak electron temperature from the Thomson scattering system with the electron temperature results from the crystal spectrometer is shown in Fig. 2. The data were obtained from a single NSTX discharge with pure Ohmic heating. For this comparison it is important to note that the Thomson data are from instantaneous measurements, which provided a radial electron temperature 
profile every $16.6 \mathrm{~ms}$, and that the x-ray spectra were integrated over time intervals of 20 ms. The first argon spectrum with sufficient statistics for electron temperature measurements was observed during the time interval from 140 to $160 \mathrm{~ms}$, since it takes about 110 to $140 \mathrm{~ms}$ to ionize argon to the helium-like charge state. The somewhat erratic oscillations in the Thomson scattering data during the time interval from 240 to $390 \mathrm{~ms}$ are ascribed to the occurrence of a magneto-hydrodynamic instability.

In conclusion, the experiments at NSTX have demonstrated that a new level of accuracy in the atomic data is needed. Especially measurements to infer the existence of nonMaxwellian electron energy distributions are extremely sensitive to small errors in the atomic satellite data. In order to adequately represent the spectra of helium-like ions and to correctly utilize their diagnostic potential for determining electron temperatures and non-Maxwellian electron energy distributions, the atomic calculations must include all possible radiative and autoionization transitions. Shortcuts that are commonly used in the calculation of the satellite line strengths may lead to erroneous assumptions of the existence of tails on the electron distribution. Although the present investigations were performed for the satellite spectra of ArXVII, we believe that our results generally apply to the spectra of helium-like ions.

We gratefully acknowledge the support by R. Hawryluk, M. Ono, and the NSTX team. This work was performed under the auspices of the U. S. Department of Energy by the Princeton Plasma Physics Laboratory under Contract No. DE-ACO2-76-CHO-3073 and by the University of California Lawrence Livermore National Laboratory under Contract No. W-7405-ENG-48 and supported in part by the Office of Fusion Energy Sciences as part of the Basic and Applied Science Initiative. LAV acknowledges support of the Russian Foundation for Basic Research under projects 00-02-17825 and 98-02-22027. 


\section{References}

(1) T. Kato, U. I. Safronova, A. S. Shlyaptseva, M. C. Cornille, J. Dubau, and J. Nilsen, Atomic and Nuclear Data Tables 67,225-329 (1997)

(2) A. H. Gabriel and K. J. H. Phillips, Mon. Not. R. Astron. Soc. 189, 319 (1979)

(3) R. Bartiromo, F. Bombarda, R. Giannella, Physical Review A 32(1), 531 (1985); J. F. Seely, U. Feldman, and G. A. Doscheck, Astroph. J. 319, 541 (1987); R. Mewe, in X-ray Spectroscopy in Astrophysics, edited by J. van Paradijs and J. A. M. Bleeker (Springer-Verlag, Berlin 1999), 109.

(4) M. Bitter S. von Goeler, K. W. Hill, R. Horton, D. Johnson, W. Roney, N. Sauthoff, E. Silver, and W. Stodiek, Phys. Rev. Lett. 47, 921 (1981).

(5) A. Hauer, K. B. Mitchell, D. B. van Hulsteyn, T. H. Tan, E. J. Linnebur, M. M. Mueller, P. C. Kepple, H. R. Griem, Phys. Rev. Lett. 45, 1495 (1980); C.F. Hooper, Jr., D.P. Kilcrease, R.C. Mancini, L. A. Woltz,D. K. Bradley,P. A. Jaanimagi, M. C. Richardson, ibid. 63, 267 (1989); B. A. Hammel, C. J. Keane, M. D. Cable, D. R. Kania, J. D. Kilkenny, R. W. Lee, and R. Pasha, ibid. 70, 1263 (1993).

(6) E. Källne, J. Källne, A. Dalgarno, E. S. Marmar, J. E. Rice, and A. Pradhan, Phys. Rev. Lett. 52, 2245 (1984); F. Bombarda, R. Gianella, E. Källne, G. J. Tallents, F. Bely-Dubau, P. Faucher, M. Cornille, J. Dubau, and A. H. Gabriel, Phys. Rev. A 37, 504 (1988); J. E. Rice, M. Greenwald, I. H. Hutchinson, E. S. Marmar, Y. Takase, S. M. Wolfe, and F. Bombarda, Nuclear Fusion 38, 75 (1998); J. Weinheimer, I. Ahmad, O. Herzog, H.J. Kunze, G. Bertschinger, W. Biel and M. Bitter, Rev. Sci. Instrum. 72, 2566 (2001).

(7) M. Bitter, K. W. Hill, L. Roquemore, P. Beiersdorfer, S. M. Kahn, S. R. Elliot, and B. Fraenkel, Rev. Sci. Instrum. 70, 292 (1999); M. Bitter, K. W. Hill, L. Roquemore, P. Beiersdorfer, D. Thorn, and Ming Feng Gu, ibid. 74, 1977 (2003)

(8) A. H. Gabriel, Mon. Not. Roy. Astron. Soc. 160, 99 (1972).

(9) M. R. Tarbutt, R. Barnsley, N. J. Peacock, and J. D. Silver, J. Phys. B: At. Mol. Opt. Phys. 34, 3979 (2001). 
(10) TFR Group, F. Bombarda. F. Bely-Dubau, P. Faucher, M. Cornille, J. Dubau, and M. Loulergue, Phys. Rev. A 32, 2374 (1985)

(11) P. Beiersdorfer, S. Chantrenne, M. H. Chen, R. E. Marrs, D. A. Vogel, K. L. Wong, and R. Zasadzinski, Z. Phy. D 21, 209 (1991)

(12) L. A. Vainshtein and U. I. Safronova, At. Data Nucl. Data Tables 21, 49 (1978); --- ibid., 25, 311 (1980)

(13) B. P. LeBlanc, R. E. Bell, D. W. Johnson, D.E. Hoffman, D.C.Long, and R. W. Palladino, Rev. Sci. Instrum. 74, 1659 (2003)

(14) M. Bitter, H. Hsuan, V. Decaux, B. Grek, K. W. Hill, R. Hulse, L. A. Kruegel, D. Johnson, S. von Goeler, and N. Zarnstorff, Phys. Rev. A 44, 1796 (1991).

(15) F. P. Keenan, S. M. McCann, and A. E. Kingston, Physica Scripta 35,432 (1987)

(16) M. F. Gu, , Astrop. J. 582, 1241 (2003) 
Table I: $\quad$ Wavelengths and $\mathrm{F}_{2}$ line factors (as defined in [10]) from the FA and $\mathrm{MZ}$ codes for some prominent dielectronic satellites

\begin{tabular}{|c|c|c|c|c|}
\hline & \multicolumn{2}{|c|}{ FA Code } & \multicolumn{2}{|c|}{ MZ Code } \\
\hline Transition & $\begin{array}{l}\lambda \\
(\AA)\end{array}$ & $\begin{array}{l}F_{2} \\
\left(10^{13} \mathrm{~s}^{-1}\right)\end{array}$ & $\begin{array}{l}\lambda \\
(\AA)\end{array}$ & $\begin{array}{l}\mathrm{F}_{2} \\
\left(10^{13} \mathrm{~s}^{-1}\right)\end{array}$ \\
\hline $1 \mathrm{~s} 2 \mathrm{p}^{2}{ }^{2} \mathrm{D}_{5 / 2}-1 \mathrm{~s}^{2} 2 \mathrm{p}^{2} \mathrm{P}_{3 / 2}(\mathbf{j})$ & 3.9936 & 23.1 & 3.9941 & 24.4 \\
\hline $1 \mathrm{~s} 2 \mathrm{p}^{2}{ }^{2} \mathrm{D}_{3 / 2}-1 \mathrm{~s}^{2} 2 \mathrm{p}^{2} \mathrm{P}_{1 / 2}(\mathbf{k})$ & 3.9896 & 17,0 & 3.9901 & 18.0 \\
\hline $1 \mathrm{~s} 2 \mathrm{p}^{2}{ }^{2} \mathrm{P}_{3 / 2}-1 \mathrm{~s}^{2} 2 \mathrm{p}^{2} \mathrm{P}_{3 / 2}$ & 3.9856 & 3.78 & 3.9860 & 4.57 \\
\hline $1 s 2 p 3 p^{2} D_{3 / 2}-1 s^{2} 3 p^{2} P_{3 / 2}$ & 3.9572 & 15.6 & 3.9567 & 18.6 \\
\hline $1 s 2 p 3 p^{2} D_{3 / 2}-1 s^{2} 3 p^{2} P_{1 / 2}$ & 3,9564 & 9.70 & 3.9557 & 11.7 \\
\hline $1 \mathrm{~s} 2 \mathrm{p} 3 \mathrm{~d}^{2} \mathrm{~F}_{7 / 2}-1 \mathrm{~s}^{2} 3 \mathrm{~d}^{2} \mathrm{D}_{5 / 2}$ & 3.9519 & 8.82 & 3.9525 & 13.5 \\
\hline $1 s 2 p 4 p{ }^{2} D_{5 / 2}-1 s 24 p{ }^{2} P_{3 / 2}$ & 3.9528 & 5.17 & 3.9532 & 7.08 \\
\hline $1 \mathrm{~s} 2 \mathrm{p} 4 \mathrm{~d}^{2} \mathrm{~F}_{7 / 2}-1 \mathrm{~s}^{2} 4 \mathrm{~d}^{2} \mathrm{D}_{5 / 2}$ & 3.9517 & 4.83 & 3.9516 & 6.09 \\
\hline $1 \mathrm{~s} 2 \mathrm{p} 4 \mathrm{p}^{2} \mathrm{D}_{3 / 2}-1 \mathrm{~s}^{2} 4 \mathrm{p}^{2} \mathrm{P}_{1 / 2}$ & 3.9526 & 3.55 & 3.9528 & 5.63 \\
\hline
\end{tabular}




\section{Figure Captions}

Figure 1: Least squares fit comparisons of a satellite spectrum of helium-like argon, ArXVII, from Ohmically heated NSTX discharges (\#105885-105890) with synthetic spectra constructed from the predictions of the MZ code $(a, b)$ and Flexible Atomic Code (c). The data were accumulated during the time interval of steady state conditions from 0.210 to 0.320 s. The $\mathrm{MZ}$ code and Flexible Atomic Code include the contributions from satellites with $\mathrm{n} \leq 6$. The total intensity and dielectronic and inner-shell excited satellite components are shown separately in the synthetic spectra. The fit in (c) employed enhancement factors for the lines $\mathbf{x}$, $\mathbf{y}, \mathbf{z}$ and $\mathbf{q}$ of $0.67,1.29,3.02$, and 0.38 , respectively. The enhancement factors for $\mathbf{x}$ and $\mathbf{z}$ are consistent with theoretical expectations for redistribution of the population between the ${ }^{3} \mathrm{P}_{2}$ and ${ }^{3} \mathrm{~S}_{1}$. The enhancement factor for $\mathbf{q}$ is a measure of the relative abundance of ArXVI and ArXVII.

Figure 2: Comparison of electron temperature results from the crystal spectrometer with the Thomson scattering results for the NSTX discharge \#108258. The Thomson scattering data represent three-point averages of the values surrounding and including the maximum of the radial profiles. 

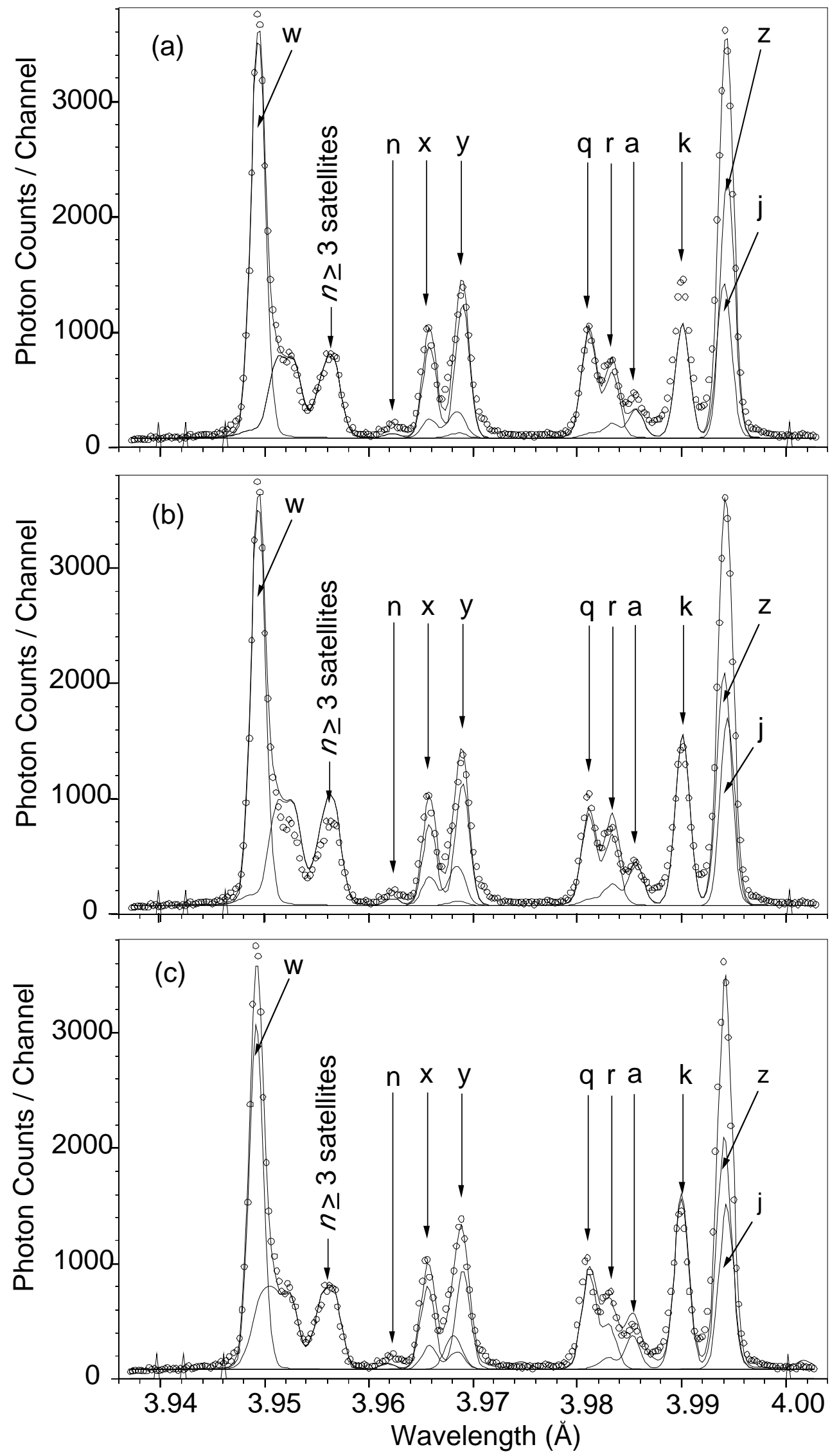


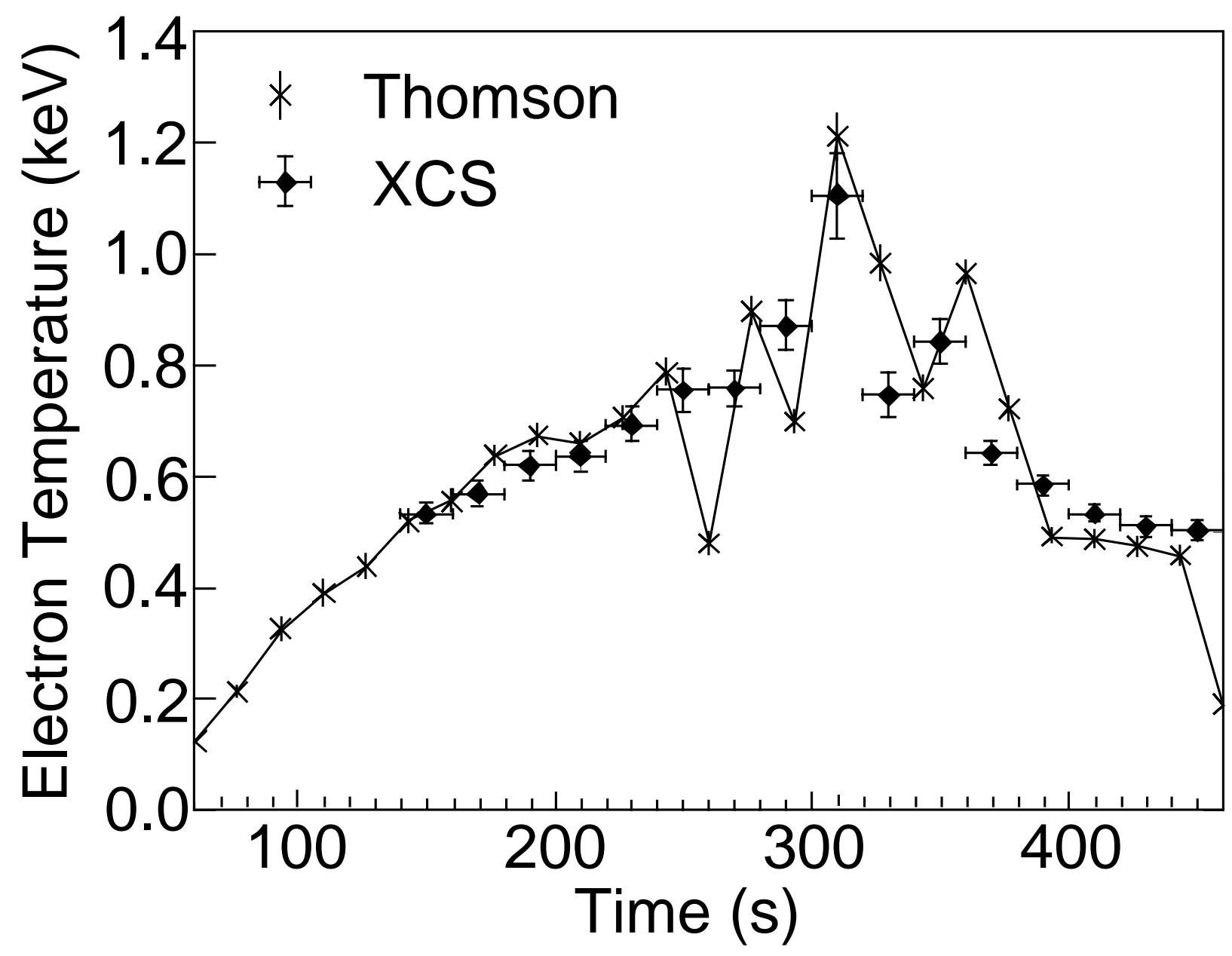




\section{External Distribution}

Plasma Research Laboratory, Australian National University, Australia

Professor I.R. Jones, Flinders University, Australia

Professor João Canalle, Instituto de Fisica DEQ/IF - UERJ, Brazil

Mr. Gerson O. Ludwig, Instituto Nacional de Pesquisas, Brazil

Dr. P.H. Sakanaka, Instituto Fisica, Brazil

The Librarian, Culham Laboratory, England

Mrs. S.A. Hutchinson, JET Library, England

Professor M.N. Bussac, Ecole Polytechnique, France

Librarian, Max-Planck-Institut für Plasmaphysik, Germany

Jolan Moldvai, Reports Library, Hungarian Academy of Sciences, Central Research Institute for Physics, Hungary

Dr. P. Kaw, Institute for Plasma Research, India

Ms. P.J. Pathak, Librarian, Institute for Plasma Research, India

Ms. Clelia De Palo, Associazione EURATOM-ENEA, Italy

Dr. G. Grosso, Instituto di Fisica del Plasma, Italy

Librarian, Naka Fusion Research Establishment, JAERI, Japan

Library, Laboratory for Complex Energy Processes, Institute for Advanced Study, Kyoto University, Japan

Research Information Center, National Institute for Fusion Science, Japan

Dr. O. Mitarai, Kyushu Tokai University, Japan

Dr. Jiangang Li, Institute of Plasma Physics, Chinese Academy of Sciences, People's Republic of China

Professor Yuping Huo, School of Physical Science and Technology, People's Republic of China

Library, Academia Sinica, Institute of Plasma Physics, People's Republic of China

Librarian, Institute of Physics, Chinese Academy of Sciences, People's Republic of China

Dr. S. Mirnov, TRINITI, Troitsk, Russian Federation, Russia

Dr. V.S. Strelkov, Kurchatov Institute, Russian Federation, Russia

Professor Peter Lukac, Katedra Fyziky Plazmy MFF UK, Mlynska dolina F-2, Komenskeho Univerzita, SK-842 15 Bratislava, Slovakia

Dr. G.S. Lee, Korea Basic Science Institute, South Korea

Institute for Plasma Research, University of Maryland, USA

Librarian, Fusion Energy Division, Oak Ridge National Laboratory, USA

Librarian, Institute of Fusion Studies, University of Texas, USA

Librarian, Magnetic Fusion Program, Lawrence Livermore National Laboratory, USA

Library, General Atomics, USA

Plasma Physics Group, Fusion Energy Research Program, University of California at San Diego, USA

Plasma Physics Library, Columbia University, USA

Alkesh Punjabi, Center for Fusion Research and Training, Hampton University, USA

Dr. W.M. Stacey, Fusion Research Center, Georgia Institute of Technology, USA

Dr. John Willis, U.S. Department of Energy, Office of Fusion Energy Sciences, USA

Mr. Paul H. Wright, Indianapolis, Indiana, USA 
The Princeton Plasma Physics Laboratory is operated by Princeton University under contract with the U.S. Department of Energy.

\author{
Information Services \\ Princeton Plasma Physics Laboratory \\ P.O. Box 451 \\ Princeton, NJ 08543
}

Phone: 609-243-2750

Fax: 609-243-2751

e-mail: pppl_info@pppl.gov

Internet Address: http://www.pppl.gov 